\title{
The Crisis and Way out of Physical Education Teacher's Self-Identity
}

\author{
Yongxing Bi \\ Department of Physical Education, Harbin Institute of Technology, Weihai, China \\ Email: byx5681561@163.com
}

How to cite this paper: Bi, Y. X. (2021). The Crisis and Way out of Physical Education Teacher's Self-Identity. Open Journal of Social Sciences, 9, 507-515. https://doi.org/10.4236/jss.2021.93033

Received: March 2, 2021

Accepted: March 24, 2021

Published: March 31, 2021

\begin{abstract}
Physical education (PE) teachers' self-identity is the primary stage of PE teachers' professional development. One major problem facing most PE teachers is their self-identity crisis, which fundamentally hinders their professional development as well. In a society where materialism and consumerism prevail, with the sense of belonging declining, the authority of P.E. teachers disappears, the sense of identity fades away, physical education teachers inquire themselves with "what is what I want", "who am I". Based on such a background, this article attempts to analyze the manifestations and the root causes of PE teachers' self-identity crisis, in order to help break the predicament and realize their ideal selves.
\end{abstract}

\section{Keywords}

Physical Education Teacher, Self-Identity, The Crisis, Way out

\section{Introduction}

The education field pays close attention to how to help teachers realize their ideal selves. New studying hotspots related to Teacher Education Quality Assurance System, professionalization of teachers and so on serves to facilitate teachers' professional development and help realize their ideal selves. Being a teacher requires self-expression and motivation. Teachers' excellent performance in their career depends on full knowledge and understanding of their own. Therefore, self-identity of teachers plays a fundamental role on the development of their career (Cai, 2014). To put it in another way, teachers' self-identity is the first priority of their occupational advancement. Studies concerning self-identity of teachers will supply theoretical guidance and reference to physical education (PE) teachers. However, relevant studies show that domestic researches on teach- 
ers' self-identity begins late, and related systematic researches on PE teachers are relatively rare, which is only partly covered in researches on PE teachers' profession development. Based on this, this paper attempts to analyze the phenomena and root causes of PE teachers' self-identity crisis, in order to breaking their career predicaments and fulfill themselves.

\section{Teachers' Self-Identity}

'Self-identity is an individual's reflective understanding of himself with reference to his own experience (Giddens, 1998), self-identity consists of two constituents: self-understanding and self-actualization. Self-understanding is an individual's appropriate assessments of environment, correct cognition of one's role and mastery of one's ideal and actual capabilities, mainly including "Who am I?", "What kind of person am I?", "What kind of person I wish to be?", "What kind of person am I supposed to be?", etc.; self-actualization originates from one's personal needs to develop and realize the ideal. Thus, self-realization can be defined as a "reflective self" developed in accordance with their experience in their career. It's a cognitive process for teachers to question, understand and orient both themselves and their occupational development, which ultimately points to the fulfillment of teachers' individual value, sense of identity and belonging. The key steps are the reflection on the past, the embrace of status quo and the construction of themselves.

\section{Characterization and Origins of PE Teachers' Self-Identity Crisis}

Since the implementation of curriculum reform in basic education, studentoriented education concepts have been advocated. It emphasizes the dominant position of the students and their growth, while teachers' living environment and space are neglected. In the prevalence of materialism and consumerism, PE teachers are embroiled by constant self-questioning, such as "Who am I?", "What kind of person am I?", "What kind of person I wish to be?", "What kind of person am I supposed to be?", etc., along with the sense of belonging dwindling, authority subsiding and sense of identity blurring. However, self-actualization is based on clear knowledge and understanding of oneself. Facts prove that those constant self-questionings of $\mathrm{PE}$ teachers have already become one major problem facing most PE teachers is their self-identity crisis, which fundamentally hinders their professional development as well.

In the context of market economy, materialized value system measuring in terms of money has already become the prominent essence for citizens' identity establishment in the modern society (Cai, 2014). Occupational traits of the teacher determine its inferiority to other vocations in material conditions. Besides, Marginalization of PE teachers' status begets their spiritual loss and impoverishment (Wang, Dong, Wang \& Lu, 2015), subsequently leading to their loss of confidence to affirm their identity. Consequently, when weighing gaining and loss, 
PE teachers falter, even grow distorted, thus fall into the crisis of self-identity.

\subsection{Inferior Sense of Identity Caused by "Poor" Income and "Inferior" Professional Status}

In market economy, economical resources are the heart of social class. Thus, income has become an important standard for the division of the stratum (Cai, 2014). Simultaneously, it turns out to be a confirmation of P.E teachers' social status and support of their social identity. According to relevant studies, wages of PE teachers are at a rather low level, even much lower when compared to their counterparts of the "main course". Interviewed PE teachers claim that 'low income mainly propelled them to reselect their job (Dong, Wang, Zhai, Wang\&Lu, 2015). With the income gap between rich and poor expand, inferior sense of social identity deriving from comparison have become their unutterable sorrow. Similar details or scenes are depicted by the many- "being exposed to the sun and wind on the campus all day" "gaining much lower than main courses teachers" "Our value can't be manifested by the job, where giving and gain are not proportional". Therefore, PE teachers' self-identity is directly wounded by traumatic mental experience deriving from meager income.

Besides, their inferior sense of identity originates from the low professional status of PE. Globally, Physical education are considered to be unconstructive, unacademic, unproductive and peripheral. It is labelled as compensational and recreational rather than educational. Consequently, P.E is of lower status, less valuable and less important. Marginalization of PE status causes PE teachers to hover between "teachers" and "custodians", falling into constant questioning of "who am I?".

\subsection{Sense of Occupational Value Impaired by Part-Time Work}

Career accomplishments and occupational influence of teaching work are more measured by the reward of spirit (Cai, 2009; Sun, 2011). However, spiritual reward for PE teachers is barely invisible in the context of test-oriented education system. Besides, influenced by market economic system, more teachers rather measure their career accomplishment by external reward like wage than spiritual compensation. According to related studies, increasing number of P.E teachers choose part time jobs because they want to improve their economic conditions and better their life quality. PE teachers' work requires a great amount of physical and mental investment. However, an individual's time and energy are finite. Thus, PE teachers' regular work and part-time job intrinsically contradict. Due to part-time job's significant demand for time and energy, such a phenomenon appears-part-time job is regarded major while regular work trifling. Some PE teachers invest all of their time and energy in part-time jobs, trivializing their work at school. Such a casual attitude towards work at school results in the loss of sense of both career accomplishment and climax experience of teaching. Consequently, improvement of economic conditions sacrifices their sense of occupational value, which consequently causes invisibly spiritual insufficiency. 
Besides, many PE teachers' passion for work are impaired by prevalent choice for part-time work, they are continuously haunted by "What do I truly pursue?". Nowadays, there's no domestic evaluation system for PE teachers, most assessments of teachers are subjective. Their wage is directly measured by quantity instead of quality. Thus, different attitudes toward work serves no purpose, resulting in PE teachers who invest their blood and sweat in school teaching questioning themselves-"What should I do?".

\subsection{Career Frustration Due to Lack in Knowledge}

In traditional education, teachers play the role of disseminator and spokesmen of knowledge. They are situated between knowledge and students. It is assumed that knowledge must be conveyed and transmitted by teachers as the media rather than learned by students themselves. In the age of information, diversified ways to gain knowledge weaken teachers' status as the knowledge authority to some extent. On the grounds that amount of knowledge increases exponentially and ways to acquire knowledge become open and justified, thus teachers no longer hold sway. Increasing number of training organizations absorbs parents, they are more and more willing to send their kids to those institutions to foster their interested sports. When they reach the age of school, they have already grasp them skillfully. Besides, some students learn their interested sports by means of internet, videos etc., and master them as well. However, those sports welcomed and learned by the students may actually be unfamiliar to the PE teachers. Those phenomena may cause sense of lack in knowledge, which finally degenerates into crisis of occupational aptitude level identification. Nowadays, curriculum reform in basic education nullifies existing experience and old practices, PE teachers' ontological security is challenged. PE teachers no longer anticipate a "stereotypical identity", simultaneously predetermined behavior mode doesn't function. All of those mentioned above generates a sense of occupational crisis. Furthermore, it makes PE teachers anxious, irritated and doubt themselves. Their self-identity is confused and blurred.

Besides, Students of different ages, genders, physical and intelligent quality, economic conditions and cultural backgrounds have the right to receive $\mathrm{PE}$ and develop their personalities. Additionally, most students' conception of PE is so greatly influenced by professional and competitive sports through media that it's deeply rooted in their mind. Students always want their PE courses could rival the professional and competitive ones, finally making them center of the attention in the public. Such phenomena challenge PE teachers to a great extent, because wishful thinking like that calls for significant responsibilities and exerts tremendous pressure-PE not only must reach its educational purpose, but have to meet those demanding needs of those students as well (Cheng, 2013).

\subsection{Loss of Direction and Confidence Caused by Awkwardness and Resignation of "Marginal People"}

Physical education, as a way of education, is always "marginalized". Its value 
only lies in "promoting the circulation of qi and blood" and "strengthening muscles and bones". As a school curriculum merely supplementary to intellectual education, it is a side course, which is often occupied, making way for the so-called main courses, and even its basic class hours are difficult to guarantee. And the physical education curriculum is regarded as the so-called activity of sports technology teaching and training based on sports; physical education teaching is regarded as the training activity of enhancing physical health, with the decomposed technical movements as the content to practice in every PE class. Compared with other main courses, the marginality of physical education makes physical education teachers have a sense of isolation, and makes them feel like "marginal people". In this crooked circumstance, physical education teachers are often forgotten in the evaluation, promotion and other aspects. The gap of status and wage render PE teachers to question themselves: "compared to other teachers, why am I pale so much in comparison of wage and status?". At this time, with the reflection of their gains and losses, it continues to affect their professional development, making them inquire themselves, such as "what kind of PE teacher should I be?” And so on while these problems accumulate, PE teachers' sense of belonging of will continue to be weakened, and the sense of identity will continue to be blurred. Amassment of these phenomena gradually dampen the enthusiasm of PE teachers with higher vocational ideals. When PE teachers doubt the value of education, the core of their profession will be in the danger of collapse, and their initial "ideal self" will also falter.

\subsection{Disorientation due to Lack of Guidance and Evaluation Mechanisms}

Goal is the compass of action. During PE teachers' process of professional development, there's a lack in corresponding references of goals. At the end of 2011, the national ministry of education issued Teacher Professional Standards in Primary and Middle School (for Trial Implementation). However, no specific standards have been developed to aim for certain courses, and existing standards fail to cover the features of PE courses, resulting in lack in goals for PE teachers to refer during their professional development (Dong, Wang, Zhai, Wang, \& Lu, 2015). Therefore, PE teachers feel disoriented and haunted by questions such as "What on earth should I do?" "What kind of PE teacher should I be?".

Besides, in the context of mark-oriented education, most teachers are assessed according to their students' grades, while the evaluation of PE teachers is devoid of "score" basis, so that some physical education teachers simply carry out PE courses with the mindset of "students do not have safety accidents". Consequently, most PE teachers just muddle through their courses due to deficiency of appropriate assessment system. Some PE teachers claim that "being nonchalant or serious about a course makes no difference." while being interviewed. Facts above prove that this inadequate evaluation mechanism fail to remind PE teachers of their obligations, affecting other teachers as well, making PE teachers lose themselves and entangled in questions such as "What should I do indeed?" "What 
type of PE teacher should I be?" and so on.

\section{Way out of PE Teachers' Self-Identity Crisis}

To help PE teachers realize their ideal self, that is, to help them develop in personalized ways, it is necessary to eliminate the crisis of PE Teachers' self-identity. With the prevalence of global education reform, not only efforts of their own but corresponding policies to guarantee their professional development are required to help raise PE teachers' self-recognition and realize their ideal selves.

\subsection{Formulate Evaluation Criteria for PE Teachers, Lead and Urge Them to Change Themselves}

PE teachers' loss of their identity in their professional development are caused by deficiency of goals to refer and lack of scientific assessment criteria (Dong, Wang, Zhai, Wang\&Lu, 2015). Therefore, evaluation standards of PE teachers can provide a clear goal for their occupational development, subsequently help them plan their occupational career, receive in-service education and training, provide criteria for professional growth and improvement, finally achieve "ideal self".

\subsection{Improve the Income of PE Teachers and Credit Their Labor Value}

PE teachers play a prominent role in making our nation prosperous and powerful. Government departments and people from all walks of life have recognized their importance, they appeal to improving PE teachers' status and their wage, in order to make sure that PE teachers immerse themselves in their career. For example, it is mentioned in the Regulations on School Physical Education that PE teachers should enjoy equal treatment with teachers of other disciplines in terms of selection, employment, salary, etc.; in the Sports Law of the People's Republic of China, schools should guarantee physical education teachers to enjoy treatment related to their work characteristics in accordance with relevant national rules and regulations; in the Outline of National Medium and long term education reform and development plan (2010-2020) It also clearly proposes to improve the status and treatment of teachers. Introduction and promulgation of those policies lay a solid foundation for improvement of PE teachers' welfare. However, during the implementation of those polices, the administrative department for education should take measures to make sure relevant polices are put into practice, provide real solutions to the problems related to PE teacher's welfare, effectively reflect their status and welfare as professionals, confirm their labor value, make them feel happy for their earnings of work, lay a solid basis for their total absorption in work.

\subsection{Build Professional Development Community for Teachers, Intensify Their Sense of Belonging}

It has become a consensus in academic field that it is required to facilitate PE 
teachers' career development by building teacher professional development community. Development of teacher's specialties relies on only not themselves but external environment for survival and development as well. Therefore, teacher professional development community is an organization providing favorable conditions for their specialties' development (Pan \& Wang, 2019). As an individual, $\mathrm{PE}$ teachers negotiate, communicate and cooperate with other individuals equally in the community, improve and surpass themselves through continuous learning. The community accentuates self-management, interactions, cooperation, share, mutual learning and assistance, eventually forming a team of mutual encouragement, assistance and improvement, offering a positive and harmonious space for teachers' specialty to survive and thrive. Thus, teacher professional development community can not only provide environment to facilitate PE teachers' professional development, but also enhance their sense of belonging in their career.

\subsection{Foster a Sense of "Only Achievements Securing the Status"}

It has become a consensus in all trades and professions that only achievements can secure the status, and one's accomplishments should match his/her status'. "accomplishments" and "status" compliment and supplement each other. "Accomplishments" is the basis and prerequisite for "status", "status" is the key and guarantee of "prerequisite". "Accomplishments" directly result in "Status". Besides, having professional achievements is the only righteous path to a higher status where one's able to showcase his talents. In other words, without accomplishments, being in a higher professional status is just a nonsense. A lift in PE teachers' professional status lies in their making a difference in their field. In some regions, PE teachers are dispensable crew in school. On the grounds that in some teachers' and leaders' perspective, everyone is able to teach PE courses. This phenomenon originates from PE teachers' doing nothing and makes sense why PE teachers' professional status is low. Thus, PE teachers should foster a sense of "only achievements securing the status", constantly improve their professional level, truly fulfill their obligations as PE teachers, make sure they "achieve something" in order to gain a higher status.

\subsection{Enhance PE Teachers' Professionally Reflective Ability}

Self-identity itself is a process of constant self-reflection. In order to reduce PE teachers' self-identity crisis, it is required to enhance their professional reflective ability. Teaching reflection is aimed at providing a means and tool for teachers to participate in teaching and professional development more actively, which is effective to improve the quality of teaching. Teaching reflection mainly includes three activities: recollection, thinking and evaluation. It mainly gives feedback on the contents, means, methods and organizational forms of the past physical education teaching; aiming at thinking, reflecting, identifying the problems existing in the past physical education teaching process, and then correcting them. 
Two main problems are involved in PE teaching process: "The first problem requires that reflection is based on belief and value, the second calls for reflections on teaching content and methods. PE teachers" reflection on teaching is a crucial segment during their professional growth, it mainly includes essays, diary and teaching plan of reflection. P.E teacher better their professional and teaching ability during reflective and exploratory teaching process. It's demanded by both the curriculum reform in basic education and their own need for development. By constantly questioning themselves "What is worth doing?" "Is what I'm doing right now effective?" through reflection, PE teachers' occupational ability is enhanced and self-identity crisis is therefore eliminated.

\section{Conclusion}

Looking at domestic PE teachers as a whole, Most PE teachers choose to continue their career in order to make a living, not for the sake of their occupational pursuit, which leads to more passive response in their career and lack of active thinking and construction. They are not clear about "what should I do?" "What kind of PE teacher should I be?" What's more, they lack criticism, reflection and transcendence, "what's worth doing", "is what I'm doing effective?". In the process of their professional growth, they are basically in the state of "muddling through". Their ideal self is ruined by self-identity crisis. Therefore, only by clarifying the core of the self-identity crisis of physical education teachers and analyzing its root causes, subsequently improving their sense of significance, identity and belonging, can they truly eliminate the self-identity crisis and realize their ideal self-identity.

\section{Conflicts of Interest}

The author declares no conflicts of interest regarding the publication of this paper.

\section{References}

Cai, C. (2014). The Difficulties and Breakthrough of the Teachers' Identity on Capital in the Changing Society. Teacher Education Research, 4, 9-15.

Cai, M. (2009). Evaluation of American Primary and Secondary School Teachers and Typical Cases. Beijing: Peking University Press.

Cheng, C. (2013). Re-Understanding of Educational Knowledge Basis of P.E. Teachers. Journal of Wuhan Institute of Physical Education, 4, 73-77.

Dong, G., Wang, J., Zhai, Y., Wang, T., \& Lu, C. (2015). The Current Situation of Professional Development of Newly Employed Physical Education Teachers in Elementary and Middle Schools in China. Journal of Physical Education, 4, 76-82.

Giddens, A. (1998). Modernity and Self-Identity. Beijing: SDX Joint Publish Company.

Pan, L., \& Wang, J. (2019). Constructing Teachers "Professional Community to Promote PE Teachers" Professional Development. Journal of Wuhan Institute of Physical Education, 5, 91-95.

Sun, H. (2011). International Comparison among Teacher Evaluation Indicator System. 
Beijing: The Commercial Press.

Wang, J., Dong, G., Wang, T., \& Lu, C. (2013). Investigation of U.S.'s Physical Education Teacher's Professional Standards in the Perspective of Humanism. Journal of Beijing Sport University, 7, 93-98. 